\title{
Resistance to antihypertensive drugs targeting Renin-Angiotensin-Aldosterone- System in cancer patients: a case series
}

\author{
Mishita Goel ${ }^{1^{*}}$ D, Rajiv Sunil Varandani ${ }^{2}$ and Tochukwu M. Okwuosa ${ }^{3}$
}

\begin{abstract}
Hypertension impacts overall prognosis in cancer patients. There are no specific recommendations for its management in these patients. We report a case series of 5 cancer patients with suboptimal BP lowering and even worsening BP with ACEi or ARBs that improved to normal upon discontinuation of these drugs.
\end{abstract}

Keywords: Hypertension, Angiotensin-converting enzyme inhibitors, Angiotensin receptor blockers, Chemotherapeutic agents

\section{Learning points}

- Hypertension is one of the most common comorbidities significantly impacting prognosis in cancer patients but still there are no specific recommendations for its management in these patients.

- Antihypertensive drugs targeting the Renin Angiotensin Aldosterone System (RAAS) are commonly used for management of hypertension in cancer patients. Preclinical studies in rats have demonstrated suboptimal blood pressure lowering effects of these agents in severe hypertension, however clinical experience with use of these agents for management of hypertension in cancer patients has never been reported.

- Our study involved 5 cancer patients with uncontrolled hypertension managed with Angiotensin-converting enzyme inhibitors (ACEi) and Angiotensin Receptor Blockers (ARBs) that later

\footnotetext{
* Correspondence: goelmishita@gmail.com

'Department of Internal Medicine, WSU/Ascension Providence Rochester Hospital, 1101 W University Drive, Rochester Drive, Rochester, MI 48307, USA Full list of author information is available at the end of the article
}

improved to normal upon discontinuation of these drugs.

- There are very few current studies that have reported beneficial outcomes in patients on antiangiogenic based cancer therapy with specific antihypertensive medication classes. Clinical experience with the use of specific anti-hypertensive medication classes in patients with cancer needs to be reported in a disciplined fashion.

\section{Introduction}

Hypertension is one of the most common comorbidities reported in cancer patients. Chemotherapeutic agents, especially VEGF signaling pathway (VSP) inhibitors can not only worsen but cause de novo hypertension [1]. There are no specific recommendations for management of hypertension in cancer patients despite its significant impact on prognosis compared to any of the other cardiovascular risk factors in these patients [2]. Angiotensin-converting enzyme inhibitors (ACEi) are most commonly used to manage hypertension. Dirix et al. [3] reported continued increase in blood pressure (BP) despite addition of an ACEi in a 51-year old male with renal cell carcinoma until treated successfully with a long acting nitrate. Thus their efficacy in reducing $\mathrm{BP}$ in cancer patients needs further exploration. 
Herein we present a case series of five cancer patients with uncontrolled hypertension while being managed with ACEi or Angiotensin Receptor Blockers (ARBs), which became controlled after discontinuation of these drugs. Baseline characteristics of these patients are indicated in Table 1.

We reviewed the charts of 5 adult cancer patients with resistant hypertension on ACEi and/or ARBs presenting to our cardio-oncology clinic over a 2 -year period. The mean of 3 clinic or 2-week ambulatory blood pressure readings before starting each $\mathrm{BP}$ medication, after starting it, following any dose change, and after discontinuation of these drugs were recorded. All 5 patients were adherent with their medications, had laboratory workup for secondary hypertension in our cardio-oncology clinic, and had normal renal artery duplex scans.

\section{Case 1}

A 77-year-old African-American female with history of IgG-Kappa multiple myeloma, aplastic anemia with Idiopathic Thrombocytopenic Purpura (requiring multiple transfusions) and type 2 diabetes mellitus (DM), presented for management of uncontrolled hypertension while being treated with bortezomib chemotherapy. Her BP log revealed systolic and diastolic blood pressure (SBP and DBP) ranges of $180-190 \mathrm{mmHg}$ and $70-80 \mathrm{mmHg}$ respectively, on an antihypertensive regimen including lisinopril $20 \mathrm{mg}$ daily, felodipine $10 \mathrm{mg}$ daily and spironolactone $25 \mathrm{mg}$ daily. Her BPs remained elevated and increased even further on higher dose lisinopril of $40 \mathrm{mg}$ daily. Lab data revealed elevated creatinine. After extensive workup, lisinopril was discontinued and carvedilol $12.5 \mathrm{mg}$ and hydralazine $25 \mathrm{mg}$ twice daily were added to her BP regimen. Her creatinine levels subsequently improved with improved $\mathrm{BP}$ readings ranging from 125 to $135 / 60-65 \mathrm{mmHg}$ (Fig. 1).

\section{Case 2}

An 85-year-old Caucasian male with multiple cardiovascular comorbidities (coronary artery disease, heart failure with preserved ejection fraction (HFpEF), DM, abdominal aortic aneurysm and brain aneurysm), Chronic Obstructive Pulmonary Disease and Aplastic anemia, was treated with External Beam Radiation Therapy (EBRT) and adjuvant androgen deprivation therapy (ADT) with Leuprolide for prostate cancer with multiple bone metastases. He presented to our cardio-oncology clinic for management of uncontrolled hypertension with SBP ranges of 140-150 $\mathrm{mmHg}$. His anti-hypertensive regimen included spironolactone $25 \mathrm{mg}$ daily, amlodipine $5 \mathrm{mg}$ daily and lisinopril $20 \mathrm{mg}$ daily. Amlodipine was discontinued due to significant lower extremity edema, and lisinopril was increased to $40 \mathrm{mg}$ daily. Subsequent 2-week BP $\log$ revealed increased SBP readings to a range of $150-160 \mathrm{mmHg}$. Lisinopril was then discontinued and hydralazine was added to his $\mathrm{BP}$ regimen. At a dose of $50 \mathrm{mg}$ QID, his BP readings normalized to $125-135 / 70-80 \mathrm{mmHg}$ (Fig. 1).

\section{Case 3}

A 79-year-old Caucasian female with BRCA2 gene mutation and Stage IIIC ovarian carcinosarcoma was referred for management of uncontrolled hypertension while on bevacizumab targeted therapy. Her BP was well controlled with spironolactone $25 \mathrm{mg}$ daily and metoprolol succinate $25 \mathrm{mg}$ BID. However due to concerns for bradycardia (HR 40-60 per min), metoprolol was discontinued. Following this, her SBP readings were slightly elevated in range of $140-150 \mathrm{mmHg}$, so lisinopril $10 \mathrm{mg}$ daily was initiated. The patient's SBP remained elevated and in fact worsened, ranging from 160 to $180 \mathrm{mmHg}$ despite an increase in lisinopril dose to $20 \mathrm{mg}$ daily. Lisinopril was then discontinued, and her BP readings normalized to $120-130 / 60-80 \mathrm{mmHg}$ after re-initiation of low dose metoprolol succinate $25 \mathrm{mg}$ BID (Fig. 1).

\section{Case 4}

A 65-year-old Caucasian female with history of stage IV ovarian cancer presented with uncontrolled BP since she

Table 1 Baseline Characteristics of the Series Patients

\begin{tabular}{|c|c|c|c|c|c|c|c|}
\hline Case & Age & Gender & Ethnicity & Cancer Type & Chemotherapy/ Radiotherapy & $\begin{array}{l}\text { Initial BP } \\
\text { Range }^{a}\end{array}$ & $\begin{array}{l}\text { Final BP } \\
\text { Range }^{b}\end{array}$ \\
\hline 1. & 77 & Female & $\begin{array}{l}\text { African- } \\
\text { American }\end{array}$ & Multiple Myeloma & Bortezomib & $\begin{array}{l}180-190 / \\
70-80\end{array}$ & $\begin{array}{l}125-135 / \\
60-65\end{array}$ \\
\hline 2. & 85 & Male & Caucasian & $\begin{array}{l}\text { Prostate Cancer with multiple bone } \\
\text { metastasis }\end{array}$ & $\begin{array}{l}\text { Androgen deprivation therapy, } \\
\text { External beam radiation therapy }\end{array}$ & $\begin{array}{l}140-150 / \\
70-80\end{array}$ & $\begin{array}{l}125-135 / \\
70-80\end{array}$ \\
\hline 3. & 79 & Female & Caucasian & $\begin{array}{l}\text { Ovarian carcino- } \\
\text { sarcoma }\end{array}$ & Bevacizumab & $\begin{array}{l}160-180 / \\
70-80\end{array}$ & $\begin{array}{l}120-130 / \\
60-80\end{array}$ \\
\hline 4. & 65 & Female & Caucasian & Ovarian cancer with metastasis & $\begin{array}{l}\text { Bevacizumab and } \\
\text { cyclophosphamide }\end{array}$ & $\begin{array}{l}160-170 / \\
90-100\end{array}$ & $\begin{array}{l}120-140 / \\
80-90\end{array}$ \\
\hline 5. & 72 & Female & Caucasian & Breast cancer & Trastuzumab & $\begin{array}{l}190-210 / \\
80-90\end{array}$ & $\begin{array}{l}110-120 / \\
56-74\end{array}$ \\
\hline
\end{tabular}

\footnotetext{
${ }^{a}$ Range of home blood pressure readings/log at presentation

${ }^{b}$ Final BP means range of home blood pressure readings/log when taken off ACEi and/or ARB

Abbreviations: ACEi Ace inhibitor, ARB Angiotensin receptor blocker
} 

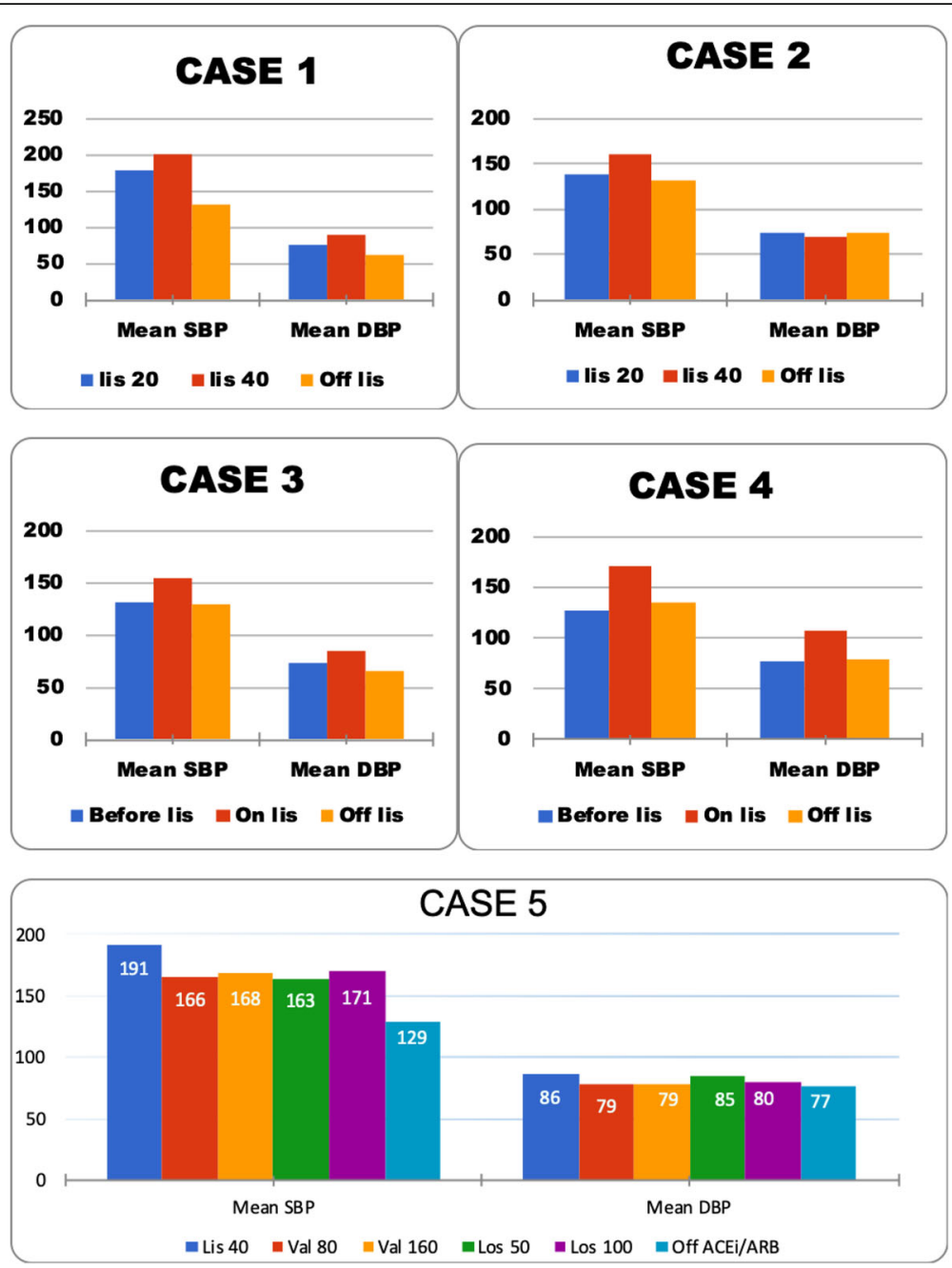

Fig. 1 Comparison of average SBP and DBP readings in: Case 1. 77 year-old female with multiple myeloma on chemotherapy with bortezomib. Graph shows SBP and DBP on low, high dose, and off ACEi therapy. Case 2. 85 year-old male on ADT with leuprolide and EBRT for prostate cancer. Graph shows SBP and DBP on low, high dose, and off ACEi therapy. Case 3. 79 year-old female on bevacizumab immunotherapy for ovarian carcinosarcoma. Data shows SBP and DBP before and after starting ACEi therapy and after discontinuing it. Case 4. 65 year-old female on

chemotherapy with bevacizumab for ovarian cancer. Data shows SBP and DBP DBP before and after starting ACEi therapy and after discontinuing it. Case 5.72 year-old female on cancer therapy with trastuzumab for breast cancer. Data shows SBP and DBP on and later off ACEi and ARB therapies

began treatment with bevacizumab and cyclophosphamide. Her hypertension had been well managed on carvedilol 12.5 mg BID prior to bevacizumab therapy, but she now had elevated BPs in the range of $160 \mathrm{~s} / 90 \mathrm{~s}$ on this drug. Lisinopril $20 \mathrm{mg}$ daily was initiated for control of her bevacizumabinduced hypertension; but her BPs increased further, ranging from 170 to $180 / 85-115 \mathrm{mmHg}$. Lisinopril was subsequently discontinued, and she was initiated on BP therapy with amlodipine $5 \mathrm{mg}$ daily. Following this change, her home BP readings significantly improved, with subsequent ranges of 120-140/80-90 mmHg (Fig. 1).

\section{Case 5}

A 72-year-old Caucasian female with history of breast cancer s/p surgery and intraoperative radiation therapy,
DM, and dyslipidemia, presented for management of uncontrolled hypertension while on cancer therapy with trastuzumab. Her SBP and DBP readings were found to be between 190 and $210 \mathrm{mmHg}$ and $80-90 \mathrm{mmHg}$ respectively on metoprolol $100 \mathrm{mg}$ daily, lisinopril $40 \mathrm{mg}$ daily, hydralazine $75 \mathrm{mg}$ TID, and chlorthalidone $25 \mathrm{mg}$ daily. Her antihypertensive regimen was adjusted to carvedilol $25 \mathrm{mg}$ BID, hydrochlorothiazide $25 \mathrm{mg}$ daily, amlodipine $10 \mathrm{mg}$ daily and losartan $50 \mathrm{mg}$ daily due to chronic cough on lisinopril. Losartan was later increased to $100 \mathrm{mg}$ daily but BP remained elevated, and even worsened on this regimen (Fig. 1). Losartan was finally switched to nifedipine $120 \mathrm{mg}$ daily; after which her BP readings declined to $120-140 / 70-80 \mathrm{mmHg}$. 


\section{Discussion}

Hypertension is the most common comorbidity seen in cancer patients. In fact many studies have shown it to be a risk factor for cancer due to abnormal proliferative pathways [4]. Cancer therapeutic agents such as bevacizumab, sunitinib, sorafenib, etc. are known to increase $\mathrm{BP}$ by decreasing endothelial nitric oxide (NO) production due to VEGF inhibition [5]. Trastuzumab, which is a humanized monoclonal antibody against HER2, also decreases VEGF expression [6]. EBRT causes a decrease in bioavailability of $\mathrm{NO}$ by impairing endotheliumdependent vasodilation of conduit arteries [7]. Other cancer therapies such as leuprolide can also cause hypertension resulting in increased cardiovascular events [8].

We observed resistance to antihypertensive agents targeting RAAS (ACEi/ARB) in our cancer patients; a phenomenon also observed in African American patients treated with ACEi/ARB monotherapy for hypertension. All of our patients had a history of hypertension prior to being initiated on chemotherapy. Their BPs were uncontrolled on ACEi/ARB but normalized on discontinuation of these agents. All of these patients reported adherence with their medications and had normal renal artery duplex scans. None of the physical exam findings or laboratory values suggested other causes of secondary hypertension.

Three of our patients were on bevacizumab and trastuzumab, which are known to decrease VEGF expression. Preclinical experiments in rats have shown an inability of ACEi to modulate higher increases in BP induced by VEGF inhibition, and suggest effectiveness in treatment for only mild increases in BP $(10-15 \mathrm{mmHg})$ [9]. They also observed reduced renin levels in the rats exposed to higher levels of cediranib (a potent VSP inhibitor), and thus concluded that RAAS gets downregulated to maintain normotension when exposed to these agents. Other preclinical studies have also shown suppression of RAAS by angiogenesis inhibition [5]. Thus, the significance of RAAS in mediating antiangiogenic therapy-induced hypertension is still controversial and other mechanisms such as inhibition of endothelial derived relaxation factors, capillary rarefaction and alteration in pressure-natriuresis relationship, as well as other vasoconstrictive pathways, play a major role [10]. Thus ACEi/ARBs can cause suboptimal BP lowering effects in cases of severe hypertension due to already suppressed RAAS in these patients. Nonetheless, in vivo studies have shown that ACEi increases release of NO and are thus recommended as first line agents for management of anti-VEGF induced hypertension [11]; especially for their renoprotective effects given higher risk of proteinuria on VSP inhibition therapy [12]. It is possible that BP control with $\mathrm{ACEi} / \mathrm{ARBs}$ in this population occurs due to angiogenesis inhibition by RAAS antagonism and not due to their direct antihypertensive action.
Recommendations for agents best used in the management of hypertension in patients on cancer therapy are variable and somewhat controversial, particularly for those on VEGF inhibitors. ACEi/ARBs are commonly preferred in cancer patients due to improved mortality outcome [13, 14]. However, as discussed, these agents could lead to suboptimal BP lowering as a result of RAAS suppression; particularly in cases of severe VEGF inhibitor-induced hypertension. This mechanism is similar to that of the repressed RAAS system leading to ACEi/ARB resistant hypertension in persons of African ancestry [15], and is a possible explanation for the uncontrolled hypertension observed in our case 1 . This patient was also on treatment with bortezomib - a proteasome inhibitor that can rarely cause endothelial dysfunction leading to hypertension and vascular dysfunction [16]. Case 2 was on cancer treatment with leuprolide ADT which is known to cause hypertension. However, the resistance to ACEi observed in Case 2 was contrary to expectation since both leuprolide and EBRT are implicated in causing hypertension by mechanisms related to impairment of endothelium-dependent vasodilation, thus, ACEi/ARBs were expected to be effective $[7,8]$. All these patients showed resistance to ACEi/ARB on different cancer therapies with malignancy being the only commonality. Indeed, patients with various cancers are known to overexpress Angiotensin II receptor 1, which is involved in BP regulation [17].

Our clinical experience shows that for those patients resistant to $\mathrm{ACEi} / \mathrm{ARBs}$, peripheral arterial vasodilators like hydralazine and dihydropyridine calcium channel blockers (CCBs) like amlodipine or nifedipine are more effective in managing hypertension in these patients. Curwen et al demonstrated reversal of marked captoprilresistant hypertension induced by cediranib in rats after treatment with nifedipine [10]. Clinical studies have also shown effective BP management with dihydropyridine CCBs after treatment with bevacizumab $[18,19]$. In a recent study by Wiliany et al. including patients with mRCC, ACEi/ARBs were not associated with decreased BP during anti-VEGF TKI treatment while CCBs and potassium sparing diuretics were associated with significant reduction in BP [20]. Furthermore, long acting nitrates that increase NO bioavailability have also been shown to effectively control hypertension in patients on antiangiogenic therapy that was refractory to ACEi and CCBs [3]. However, there is a potential risk of compromising antiangiogenic benefits as preclinical evidence suggest the role of endothelial NO production in VEGF associated angiogenesis [21, 22].

In conclusion, possible mechanisms of hypertension resistant to $\mathrm{ACEi} / \mathrm{ARB}$ observed in certain cancer patients include overexpression of Angiotensin II receptor 1 , low renin state or RAAS suppression. Thus, the 
efficacy of drugs targeting RAAS for BP control in this population on active VEGF-inhibitor or other cancer therapy is still unclear. Since there are no specific recommendations for management of hypertension in cancer patients, clinical experience with its management needs to be reported. The observation of difficult-totreat hypertension with ACEi/ARBs in cancer patients on VSP inhibitor or other therapy requires further investigation.

\begin{abstract}
Abbreviations
ACEi: Angiotensin-Converting Enzyme inhibitors; ARBs: Angiotensin Receptor Blockers; VSP: Vascular Signaling Pathway; HER2: Human Epidermal Growth Factor receptor 2; RCC: Renal Cell Carcinoma; DM: Diabetes Mellitus; BP: Blood Pressure; SBP: Systolic Blood Pressure; DBP: Diastolic Blood Pressure; QID: 4 times daily; HR: Heart rate; PAl: Plasminogen activator inhibitor; NO: Nitric Oxide; RAAS: Renin Angiotensin Aldosterone System; VEGF: Vascular Endothelial Growth Factor; CCBs: Calcium channel blockers
\end{abstract}

\section{Acknowledgements}

Not applicable.

\section{Authors' contributions}

MG did literature search and had major contribution in writing the manuscript. RV helped in extraction of patient data and contributed in writing the manuscript. TO managed these patients and edited the entire manuscript. The author(s) read and approved the final manuscript.

\section{Funding}

No source of funding

\section{Availability of data and materials}

Data sharing is not applicable to this article as no datasets were generated or analyzed during the current study.

\section{Ethics approval and consent to participate}

Not applicable.

\section{Consent for publication}

Patient's consent obtained.

\section{Competing interests}

The authors declare that they have no competing interests.

\section{Author details}

'Department of Internal Medicine, WSU/Ascension Providence Rochester Hospital, 1101 W University Drive, Rochester Drive, Rochester, MI 48307, USA. ${ }^{2}$ Chicago College of Osteopathic Medicine, Midwestern University, Chicago, IL, USA. ${ }^{3}$ Department of Internal Medicine, Rush University Medical Center, Chicago, IL, USA.

Received: 2 April 2020 Accepted: 20 August 2020

Published online: 27 August 2020

\section{References}

1. Piccirillo JF, Tierney RM, Costas I, Grove L, Spitznagel EL Jr. Prognostic importance of comorbidity in a hospital-based cancer registry. JAMA. 2004; 291(20):2441-7.

2. Meacham LR, Chow EJ, Ness KK, et al. Cardiovascular risk factors in adult survivors of pediatric cancer--a report from the childhood cancer survivor study. Cancer Epidemiol Biomark Prev. 2010;19(1):170-81.

3. Dirix LY, Maes H, Sweldens C. Treatment of arterial hypertension (AHT) associated with angiogenesis inhibitors. Ann Oncol. 2007;18(6):1121-2.

4. Hamet P. Cancer and hypertension. An unresolved issue. Hypertension. 1996;28(3):321-4.

5. Kappers MHW, van Esch JHM, Sluiter W, Sleijfer S, Danser AHJ, van den Meiracker AH. Hypertension induced by the tyrosine kinase inhibitor sunitinib is associated with increased circulating endothelin-1 levels. Hypertension. 2010;56(4):675-81.
6. Le X-F, Mao W, Lu C, et al. Specific blockade of VEGF and HER2 pathways results in greater growth inhibition of breast cancer xenografts that overexpress HER2. Cell Cycle. 2008;7(23):3747-58.

7. Beckman JA, Thakore A, Kalinowski BH, Harris JR, Creager MA. Radiation therapy impairs endothelium-dependent vasodilation in humans. J Am Coll Cardiol. 2001:37(3):761-5.

8. Levine GN, D'Amico AV, Berger P, et al. Androgen-deprivation therapy in prostate cancer and cardiovascular risk: a science advisory from the American Heart Association, American Cancer Society, and American urological association: endorsed by the American Society for Radiation Oncology. Circulation. 2010;121(6):833-40.

9. Curwen JO, Musgrove HL, Kendrew J, Richmond GHP, Ogilvie DJ, Wedge SR Inhibition of vascular endothelial growth factor-a signaling induces hypertension: examining the effect of cediranib (recentin; AZD2171) treatment on blood pressure in rat and the use of concomitant antihypertensive therapy. Clin Cancer Res. 2008;14(10):3124-31.

10. Robinson ES, Khankin EV, Karumanchi SA, Humphreys BD. Hypertension induced by vascular endothelial growth factor signaling pathway inhibition: mechanisms and potential use as a biomarker. Semin Nephrol. 2010;30(6):591-601.

11. Pande A, Lombardo J, Spangenthal E, Javle M. Hypertension secondary to anti-angiogenic therapy: experience with bevacizumab. Anticancer Res. 2007:27(5B):3465-70

12. Derosa L, Izzedine H, Albiges L, Escudier B. Hypertension and angiotensin system inhibitors in patients with metastatic renal cell carcinoma. Oncol Rev. 2016;10(2):298.

13. McKay RR, Rodriguez GE, Lin $X$, et al. Angiotensin system inhibitors and survival outcomes in patients with metastatic renal cell carcinoma. Clin Cancer Res. 2015;21(11):2471-9. https://doi.org/10.1158/1078-0432.ccr-14-2332.

14. Song T, Choi CH, Kim MK, Kim M-L, Yun BS, Seong SJ. The effect of angiotensin system inhibitors (angiotensin-converting enzyme inhibitors or angiotensin receptor blockers) on cancer recurrence and survival. Eur J Cancer Prev. 2017;26(1):78-85. https://doi.org/10.1097/cej. 0000000000000269.

15. Brewster $L M$, Seedat YK. Why do hypertensive patients of African ancestry respond better to calciumblockers and diuretics than to ACE inhibitors and $\beta$-adrenergic blockers? Asystematic review. BMC Med. 2013;11(1). https://doi. org/10.1186/1741-7015-11-141.

16. Waxman AJ, Clasen S, Hwang W-T, et al. Carfilzomib-associated cardiovascular adverse events: a systematic review and meta-analysis. JAMA Oncol. 2018;4(3):e174519.

17. Rasha F, Ramalingam L, Gollahon $L$, et al. Mechanisms linking the reninangiotensin system, obesity, and breast cancer. Endocr Relat Cancer. 2019; 26(12):R653-72.

18. Mir $\mathrm{O}$, Coriat $\mathrm{R}$, Ropert $\mathrm{S}$, et al. Treatment of bevacizumab-induced hypertension by amlodipine. Investig New Drugs. 2012;30(2):702-7.

19. Hurwitz H, Fehrenbacher L, Novotny W, et al. Bevacizumab plus irinotecan, fluorouracil, and leucovorin for metastatic colorectal cancer. N Engl J Med. 2004;350(23):2335-42

20. Waliany S, Sainani KL, Park LS, Zhang CA, Srinivas S, Witteles RM. Increase in blood pressure associated with tyrosine kinase inhibitors targeting vascular endothelial growth factor. JACC: CardioOncology. 2019;1(1):24-36. https:// doi.org/10.1016/j.jaccao.2019.08.012

21. Cooke JP, Losordo DW. Nitric oxide and angiogenesis. Circulation. 2002; 105(18):2133-5.

22. Fukumura D, Gohongi T, Kadambi A, et al. Predominant role of endothelial nitric oxide synthase in vascular endothelial growth factor-induced angiogenesis and vascular permeability. Proc Natl Acad Sci U S A. 2001; 98(5):2604-9.

\section{Publisher's Note}

Springer Nature remains neutral with regard to jurisdictional claims in published maps and institutional affiliations. 